This item was submitted to Loughborough's Research Repository by the author.

Items in Figshare are protected by copyright, with all rights reserved, unless otherwise indicated.

\title{
Congestion charging: selling the concept
}

PLEASE CITE THE PUBLISHED VERSION

PUBLISHER

(c) Thomas Telford

VERSION

VoR (Version of Record)

LICENCE

CC BY-NC-ND 4.0

REPOSITORY RECORD

Ison, Stephen G.. 2019. "Congestion Charging: Selling the Concept”. figshare. https://hdl.handle.net/2134/4330. 
This item was submitted to Loughborough's Institutional Repository (https://dspace.lboro.ac.uk/) by the author and is made available under the following Creative Commons Licence conditions.

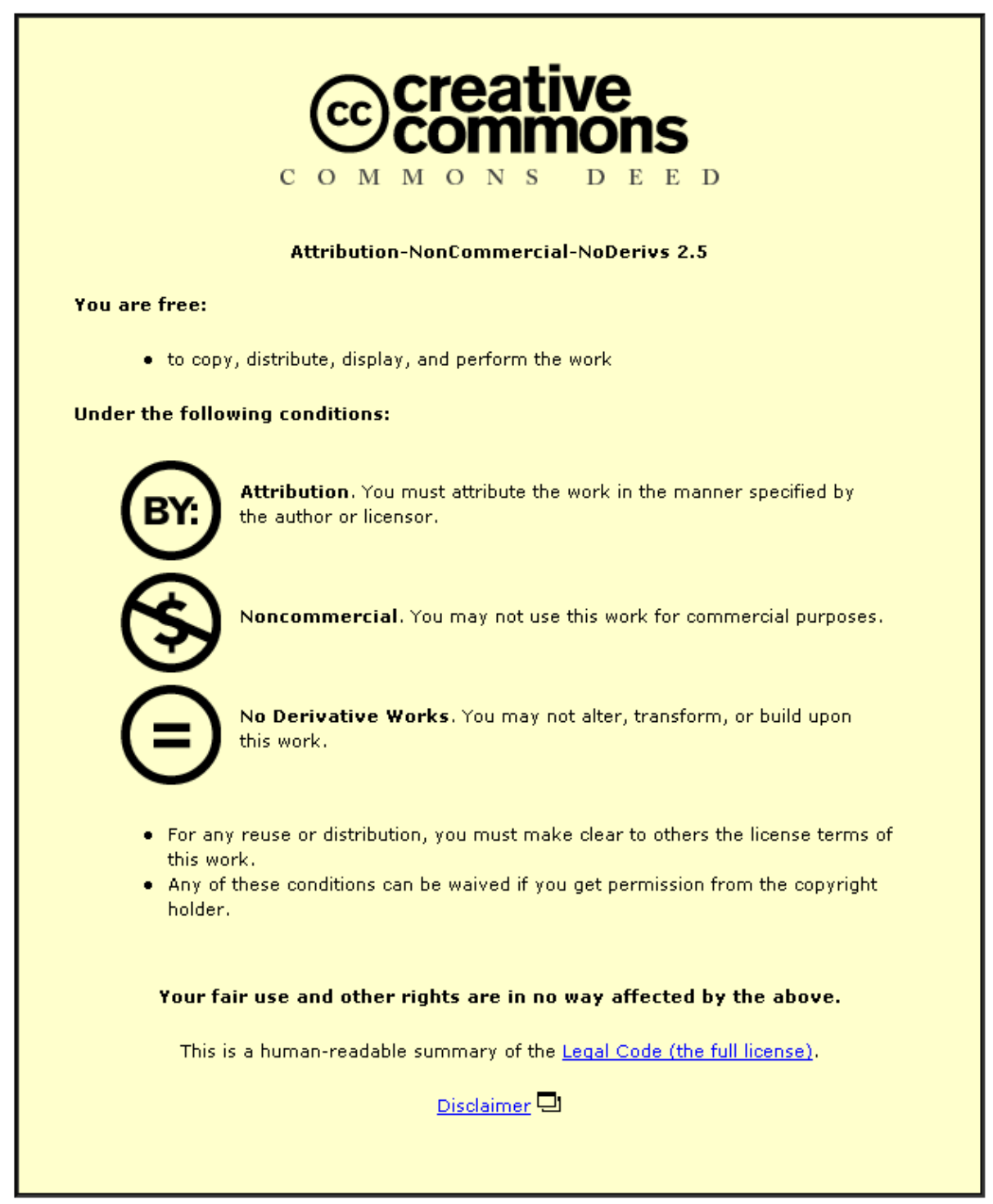

For the full text of this licence, please go to: http://creativecommons.org/licenses/by-nc-nd/2.5/ 


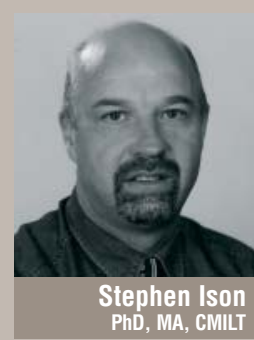

PhD, MA, CMILT

is transport studies lecturer at

Loughborough University

\section{Congestion charging: selling the concept}

The surge in urban traffic worldwide is leading to increasing problems of congestion and environmental degradation. Congestion charging is coming to be seen as one of the more effective policy options - particularly since the introduction of the central London scheme in 2003_-but it remains highly controversial. This paper describes the issues of public and political acceptance and the economic arguments for congestion pricing. It also looks at the issues that need to be addressed by authorities contemplating the introduction of a charge, including use of revenue, accuracy and reliability of the monitoring technology, availability of alternatives to cars, promotion, and the importance of positive political will and leadership.

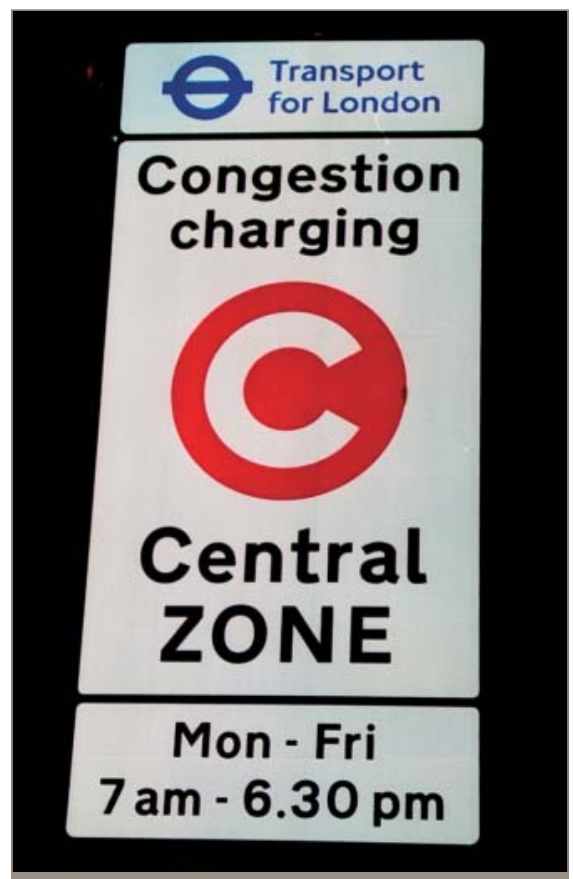

Fig. 1. Congestion charging was successfully introduced in central London in February 2003 (courtesy of Marcus Enoch, www.transfoto.com)
Traffic congestion currently represents a major problem and thus a key political issue in many urban areas worldwide, both in terms of congestion and its environmental impact. For example, Jones ${ }^{1}$ states that

'Various opinion surveys carried out in the UK in the last few years have confirmed that traffic congestion, and the road safety and environmental implications of traffic, are at the forefront of most people's minds. Nationally, around $80 \%$ of adults regard current traffic levels in general as posing a 'very' or 'fairly serious' problem. Concern about traffic-related problems rises to an overwhelming $95 \%$ when people are asked about congestion and pollution in larger towns and cities.'

In response there are a range of policy instruments for dealing with traffic-related issues in urban areas, ${ }^{2}$ one such option being congestion charging. A major diffi- 
culty with congestion charging, however, is its acceptance publicly and therefore politically. This paper briefly outlines the issue of acceptance relating to congestion charging and the economic principles underpinning the concept.

Clearly a number of issues need to be addressed if congestion charging is to become more acceptable and this paper details these issues, which are seen as central in terms of selling the concept. Most notably these include clearly stating

now the revenue raised from congestion charging is to be used

that it will tackle congestion

- the accuracy and reliability of the technology being considered

- the provision of alternatives to the private car

- how congestion charging is promoted positive political will and leadership.

This paper deals with each of these aspects in turn.

The issues are by no means exhaustive but they do, in the opinion of the author, represent the main aspects that need to be addressed by any authority contemplating the introduction of a congestion-charging scheme. Since central London successfully

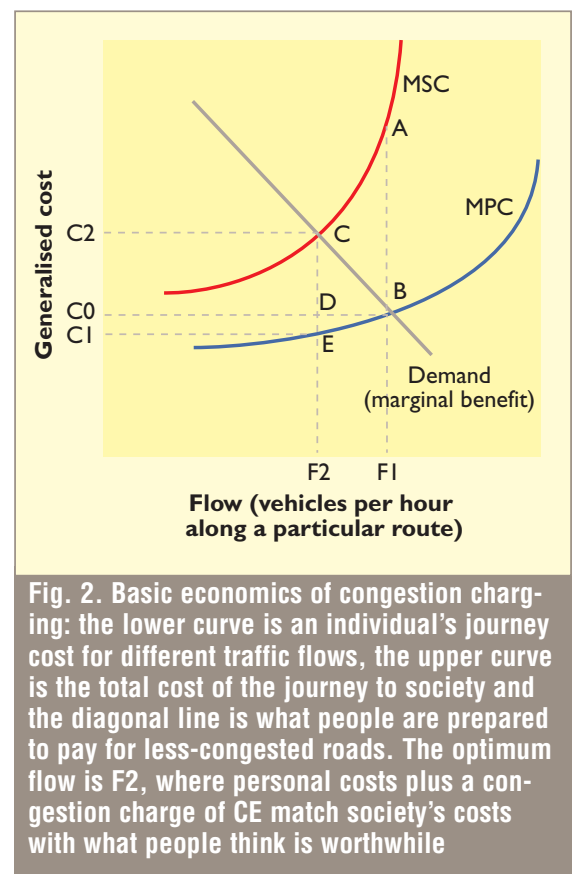

implemented a congestion-charging scheme in February 2003 (Fig. 1) reference will be made to aspects of that scheme wherever possible throughout the paper.

\section{Effectiveness and acceptance}

In terms of selling the benefits of congestion charging, Table 1 reveals the scale of the problem. It presents selected findings from a UK survey undertaken by the author in the late 1990s. The aim of the survey was to ascertain the opinions of local politicians, transport officials within metropolitan, county and district councils and selected transport academics in terms of various policy options for reducing traffic congestion in urban areas within the UK. ${ }^{3,4}$

The table reveals that the implementation of congestion charging is seen as an effective way of dealing with the problem of urban traffic congestion, with $82 \%$ of respondents viewing the option as either totally or fairly effective. The implementation of a congestion charge is perceived as being more effective than other marketand non-market-based options such as an increase in the price of petrol, cheaper public transport fares and improved public transport. In terms of acceptance, however, the situation is somewhat different with only $11 \%$ of respondents perceiving the implementation of congestion charging as being acceptable (either totally or fairly). Cheaper public transport fares and improved public transport are, perhaps not surprisingly, seen as being much more acceptable.

The retail sector has been vocal in terms of the impact the central London conges- tion charge is having on its business. A report published on the impact of the charge on the retail sector ${ }^{5}$ estimated the effect of the charge to be a $5.52 \%$ drop in sales experienced by John Lewis's Oxford Street store. As stated by Transport for London, ${ }^{6}$ however, congestion charging was introduced in a period when economic activity in central London was being affected by a number of factors, most notably instability linked to the Iraq war and its impact on tourism and the closure of London Underground's Central line. Clearly any new scheme has to be sold to key stakeholders, not least businesses operating within the charging zone.

There is thus a dilemma for decision makers contemplating the introduction of a congestion charge, it being seen as an effective but unacceptable policy measure. As such, there is a need to sell congestion charging as a policy option.

\section{Economic background}

Congestion charging as a market-based approach to dealing with excessive traffic in urban areas has long been advocated, in one form or other, particularly by economists. $^{7,8}$

In 1998 the UK Government expressed interest in congestion charging with the publication of the white paper $A$ New Deal for Transport, ${ }^{9}$ which stated it would

introduce legislation to allow local authorities to charge road users so as to reduce congestion, as part of a package of measures in a local transport plan that would include improving public transport'.
Table 1. Effectiveness and acceptability of policy options for dealing with traffic congestion in urban areas $^{3}$

\section{Policy measures}

Selective expansion of road construction in urban areas

An increase in the price of petrol to $£ 5$ per gallon

Cheaper public transport fares

An improvement in the frequency and reliability of public transport

Implementation of congestion charging

Banning/restricting of vehicles in central areas

$\begin{array}{cc}\text { Effective: } \% & \text { Acceptable: } \% \\ 35 & 27 \\ 62 & 6 \\ 65 & 92 \\ 77 & 94 \\ 82 & 11 \\ 87 & 38\end{array}$


The Transport Act 2000 did just that by giving local authorities in England and Wales the ability to charge users of road space so long as the revenue raised was directed at improvements in transport. The same power was given to local authorities in Scotland (Transport (Scotland) Act 2001) and the Greater London Authority Act 1999 gave that authority the power to introduce congestion charging in London.

The basic economics of congestion charging are illustrated in Fig. $2 .{ }^{10}$ The figure illustrates the cost of travel and the flow of vehicles along a particular congested urban route. The generalised costs of travel refers to vehicle operating costs, whether cars or goods vehicles (namely fuel, oil and maintenance costs), and the travel time. The horizontal axis measures the flow of vehicles per hour along the particular route in question and the demand line is a measure of the marginal benefit obtained by the road users from undertaking the journey during the peak period. Motorists and goods vehicle drivers are not likely to take account of the cost imposed on other road users when undertaking a journey, namely the congestion cost, since they will only consider their own 'marginal private cost' (MPC).

The MPC curve represents the price of fuel and oil, the wear and tear on the vehicle and the money value of the time spent travelling. There are however additional costs on other road users, which the motorist has not taken into account. Adding the congestion cost to the private cost will produce the "marginal social cost' curve (MSC). As the flow of vehicles increases during congested periods there will be a divergence between the MPC and MSC, mainly as a result of the increased travel times, since an extra vehicle entering the queue of traffic will impose additional delays on every other vehicle. Road users will not however take the cost of that delay into account when deciding whether or not to undertake a particular journey.

If demand, which represents the marginal benefit, is as given in Fig. 2 then the flow of traffic would be F1 where the demand line intersects the MPC curve (at point $\mathrm{B}$ ). As such, the private cost would be $\mathrm{CO}$ and the congestion cost, not taken into account by road users, would be AB.
At a flow of F1 there is what economists call a 'welfare loss' of $\mathrm{ABC}$ since that is the area which relates by how much cost outweighs the benefit to society. F2 represents the optimal flow of traffic and can be achieved, in theory at least, by imposing a congestion charge of $\mathrm{CE}$ on the road user, so that the MSC (MPC plus congestion cost) equates to the marginal benefit (represented by point C). At F2 there is no welfare loss and what has been achieved is called a 'social optimum', though it is important to note that Fig. 2 has not taken the environmental impact of road traffic into account.

The question is: how should the notion of improved welfare and social optimum be best sold to the general public and road users in particular?

\section{Use of revenue}

Assuming all motorists possess the same value of time, then the implementing agency is the main beneficiary from the introduction of a congestion charge. It is possible to analyse this using Fig 2 . Following the introduction of a congestion charge equal to $\mathrm{CE}$, the implementing authority will receive revenue from the charge equal to the area $\mathrm{C} 1 \mathrm{C} 2 \mathrm{CE}$. This revenue needs to be carefully utilised since there will be two aggrieved groups of road users following the introduction of the charge

those who continue to use their vehicles but have to pay for the privilege

- those who can no longer afford to, or choose not to use the road.

In terms of those who continue to use the road after the charge is introduced, they would appear to be better off since they have obtained time-cost savings equal to the area C1C0DE. This has been achieved due to the reduction in congestion following the introduction of the charge and hence a reduction in journey times taken. In order to achieve this benefit, however, the motorists have paid revenue to the authority totalling C1C2CE.

As such, road users experience a loss equal to the area COC2CD and, whereas they benefit from reduced travel times, they have in fact exchanged money for the time privilege. This being so it is impor- tant when selling the benefits of congestion charging that careful consideration is given to how the revenue raised from the charge is used. This is not only the case since motorists continuing to use the road pay $\mathrm{C} 1 \mathrm{C} 2 \mathrm{CE}$ and only receive a benefit of C1CODE, but also because those who are 'priced off the road' would be looking to improved public transport as an alternative. This issue was recognised by the Department for Transport, which stated in the consultation paper Breaking the Logjam $^{11}$ that

'local authorities which bring forward pilot road user charging schemes should be able to retain $100 \%$ of the net revenue generated for at least ten years from the implementation of a scheme-provided that there are worthwhile transport-related projects to be funded'.

In terms of the introduction of congestion charging in central London in February 2003, hypothecation appears to have been all-important. In the central London scheme it was estimated that for 2003-2004, £84 million of the anticipated revenue would be spent on bus improvements, $£ 36$ million on road safety measures, $£ 4$ million on closed-circuit television on buses and $£ 6$ million on developing safer routes for children to take to school. ${ }^{12}$ Projected net revenue for $2004 / 5$ is $£ 90$ million.

Earmarking the revenue raised would appear crucial to the selling and ultimate implementation of any congestion-charging scheme.

\section{Tackling congestion}

Congestion is also a concern of the UK Government, which states that 'congestion is a serious problem in many towns and cities in the main morning and evening peak periods, and for much of the day in inner and central London'. ${ }^{12}$ The question raised however is whether congestion is severe enough for a policy such as congestion charging to be implemented.

Take Hong Kong for example. Since the mid-1980s Hong Kong has considered the introduction of some form of congestioncharging scheme. ${ }^{13}$ But the Hong Kong authorities currently predict that the pri- 


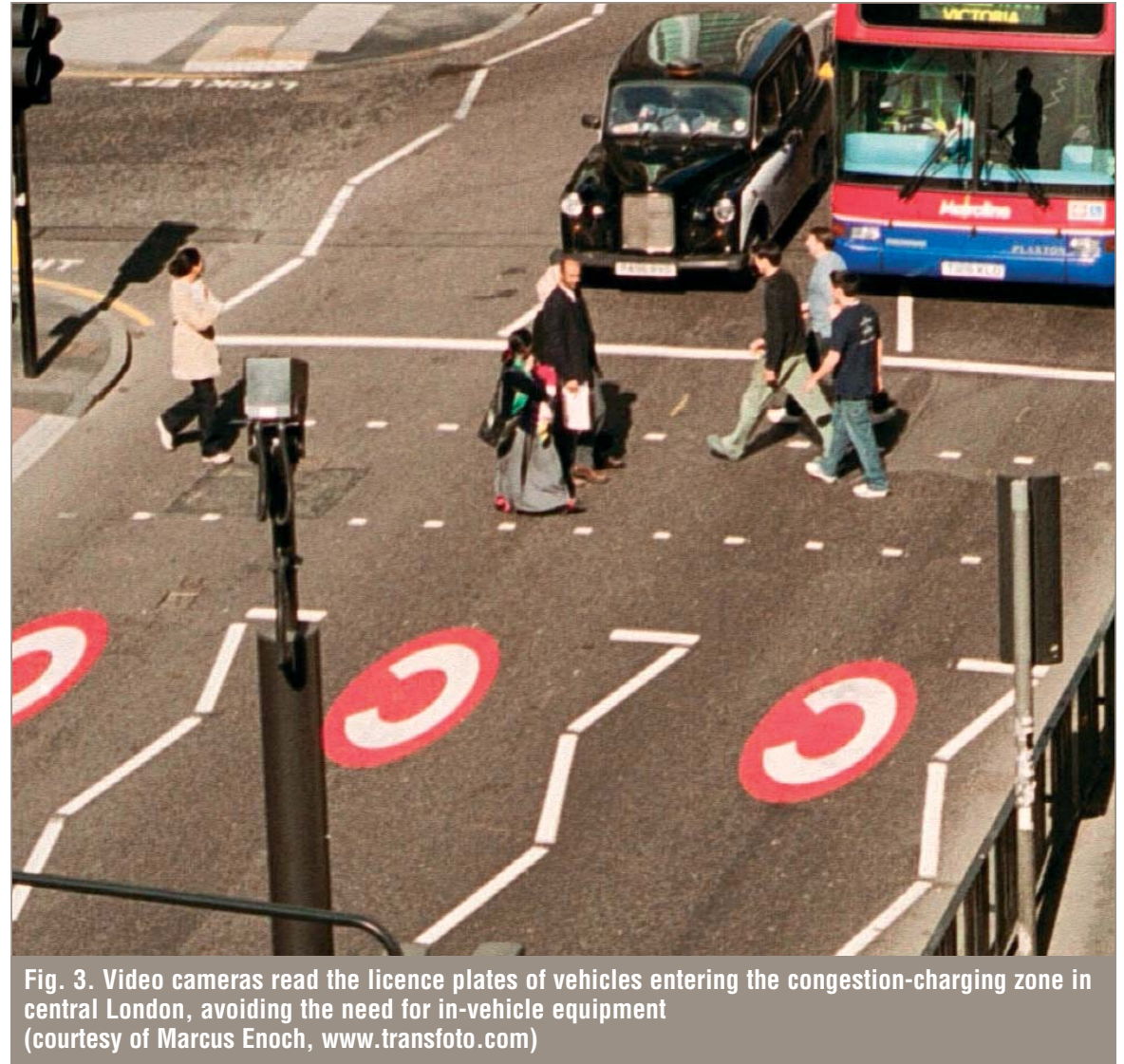

Table 2. Average trafific speeds in the central area of London: $1977-2003^{14}$

\begin{tabular}{|c|c|c|}
\hline Years & $\begin{array}{l}\text { Morning peak average traffic } \\
\text { speed: } \mathrm{km} / \mathrm{h}\end{array}$ & $\begin{array}{l}\text { Evening peak average traffic } \\
\text { speed: } \mathrm{km} / \mathrm{h}\end{array}$ \\
\hline 1977-1982 & 19.5 & 19.4 \\
\hline 1983-1990 & 18.7 & 18.1 \\
\hline 1990-1997 & 17.0 & 17.0 \\
\hline $1997-2000$ & 16.0 & 16.3 \\
\hline $2000-2003$ & 15.8 & 15.4 \\
\hline
\end{tabular}

90\% of London residents believed that there was too much traffic in the capital and $41 \%$ felt that a congestion charge was the best way to raise the revenue necessary for improving public transport vate vehicle fleet will not grow more than $3 \%$ per annum and that the traffic conditions are not too dissimilar to those experienced over the last 20 years. In addition, the central Wan Chai bypass is currently under construction and all-in-all traffic speeds are also projected to be higher than those currently experienced in cities like Tokyo, New York and central London. All of this means that the current conditions in terms of congestion in Hong Kong do not warrant the introduction of an additional restraint measure such as congestion charging.

The situation in central London, however, did warrant such a measure being considered and ultimately introduced. Table 2 reveals that the average traffic speed in the central area of London during the morning and evening peak periods were $19.5 \mathrm{~km} / \mathrm{h}$ and $19.4 \mathrm{~km} / \mathrm{h}$ respectively in 1977-1982. ${ }^{14}$ By 2000-2003 however, the average speeds had fallen to $15.8 \mathrm{~km} / \mathrm{h}$ and $15.4 \mathrm{~km} / \mathrm{h}$ respectivelybefore the introduction of congestion charging in central London. Such speeds have implications in terms of its cost to road users, as illustrated in Fig. 2, with the gap between the MPC and MSC curves reaching unacceptable levels.

Londoners were of the opinion that radical measures were required since traffic levels in London had reached unacceptable levels. For example, the Road Charging Options for London report ${ }^{15}$ stated that $90 \%$ of London residents believed that there was too much traffic in the capital and $41 \%$ felt that a congestion charge was the best way to raise the revenue necessary for improving public transport in London.

\section{Accurate and reliable technology}

Individuals are often sceptical of technology and, as such, care is required when selling the particular type of technology being considered. In terms of Fig. 2 it is important to note that the optimum charge of CE is a theoretical ideal and one that is difficult to achieve in practice. If the charge were to directly account for the congestion caused, then it would need to vary depending on the time of day and the level of congestion experienced. This would require a sophisticated scheme in terms of the technology utilised and, 
whereas such a scheme has been considered-namely congestion metering in the city of Cambridge ${ }^{16}$ - it would appear to be more difficult to sell such a concept.

Even though advances have been made in technology, a simple scheme-at least in the first instance-would seem to offer the most considered way forward, bearing in mind the need to 'sell' the technology. It may simply involve initially getting a scheme in place with no attempt to change driver behaviour; getting the motorist used to the idea before adopting a charge somewhere close to CE in Fig. 2.

In terms of technologies, there are currently a number either in operation or which have been considered, most notably

dedicated short-range communications systems

wide-area communications-based systems

video-based license-plate recognition. ${ }^{17}$

Dedicated short-range communications systems require roadside equipment with vehicles fitted with transponders. The roadside equipment and the transponders interact and a charge is made for using the road. If this does not occur then, in order to allow enforcement, the vehicle's number plate will be recorded.

Wide-area communications-based systems utilise the global positioning system to allow vehicles to be accurately located. Video-based license-plate recognition, on the other hand, involves the reading of vehicle number plates in order to identify, charge and ultimately enforce the congestion charging system. Its main advantage is that it does away with the need for invehicle equipment. This is the system currently used in central London (Fig. 3).

Launched in February 2003, the London scheme covers $21 \mathrm{~km}^{2}$. A charge of $£ 5$ (equivalent to $€ 7.40$ ) is imposed to drive into and within the charging zone and, as stated, the scheme is enforced by the use of video cameras scanning the rear number plate of vehicles entering, leaving or simply moving within the zone during the charging period. Payment to travel within the zone can be made at shops and petrol stations, via the internet or by telephone. There are penalties for non-payment. The $£ 5$ charge was set with the expectation of reducing congestion some-

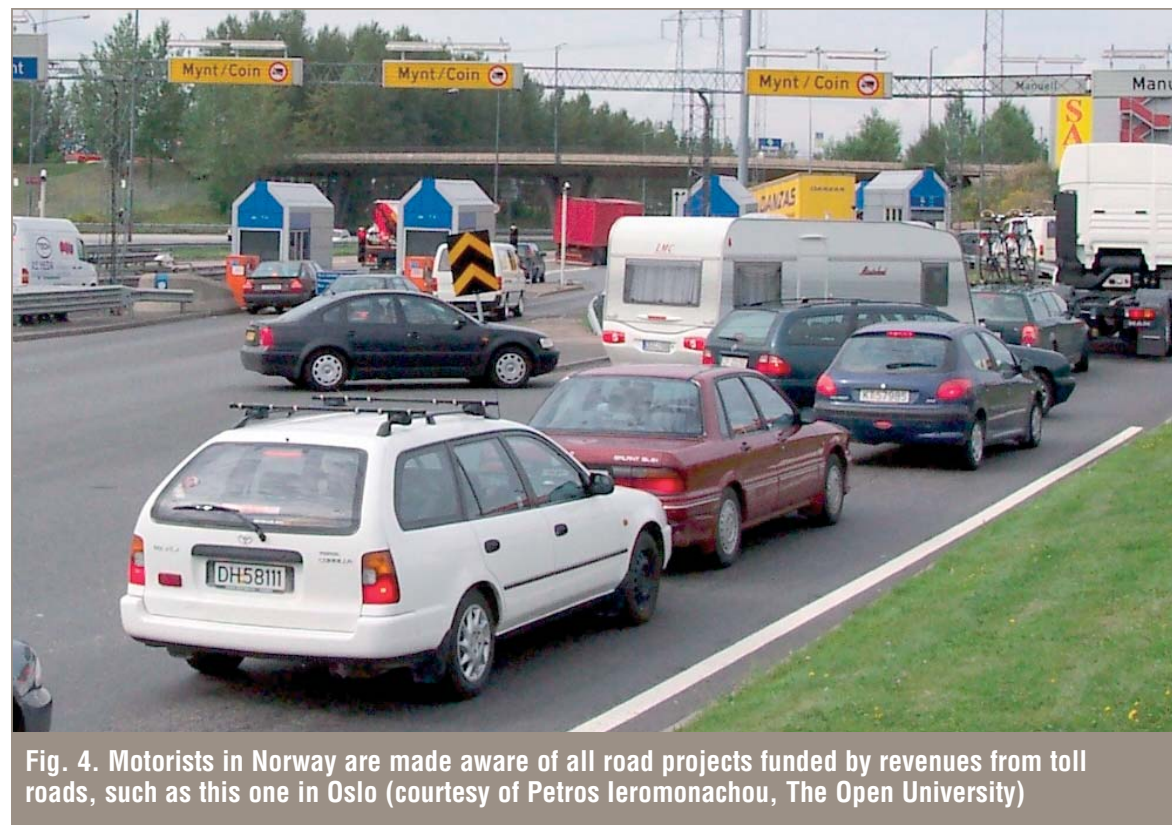

where between $20 \%$ and $30 \%$. Charging in fact resulted in congestion being reduced by around $30 \% .6$ The charge will increase to $£ 8$ from July 2005 .

In terms of the central London scheme, the recommendations of the Road Charging Options for London study 15 were taken on board. The study stated that any mayor of London wishing to implement a charging scheme at the earliest opportunity would need to use a lessadvanced system. Licence plate recognition is one such scheme, albeit one that has been successful in bringing about a desirable reduction in congestion.

Care is required however when selling such a scheme in that it needs to be accurate, reliable and free from widespread evasion. Such evasion would bring the congestion-charging scheme into disrepute. Clearly a scheme involving registration of vehicle licence plates on a database, like the central London scheme, is open to fraud and evasion. To counter evasion, a phased programme of enforcement improvements has been introduced in $2003 / 2004$. The number of penalty charge notices increased accordingly, with an average between October and December 2003 of 165000 per month. ${ }^{6}$

\section{Provision of alternatives}

As stated earlier, when selling the concept of congestion charging, it is impor- tant to pay close attention to the provision of alternatives so as to offset the potential impacts of a charging scheme. What is clear from the successful introduction of congestion charging in central London is that it is not a stand alone policy but was introduced as part of a package of measures, not least the increase in bus capacity by over 11000 spaces, to take account of the expected increase in bus patronage following the introduction of congestion charging.

\section{Promotion vital}

In selling any concept there is a need for careful promotion and this is particularly the case in terms of congestion charging. It involves stating clearly why a particular congestion-charging scheme is required and how the revenue raised from that scheme will be allocated.

In the Norwegian case of toll rings, for example (Fig. 4), the Norwegian National Roads Administration responsible for the projects financed by the tolls have in the past erected signs close to construction sites informing motorists that the projects have been financed via the revenue raised from the toll. This can be seen as a rather basic approach, but nevertheless it is a visible sign that the tolls are not just another general revenue-raising measure.

Promoting the concept aids in gaining the confidence of the general public and 


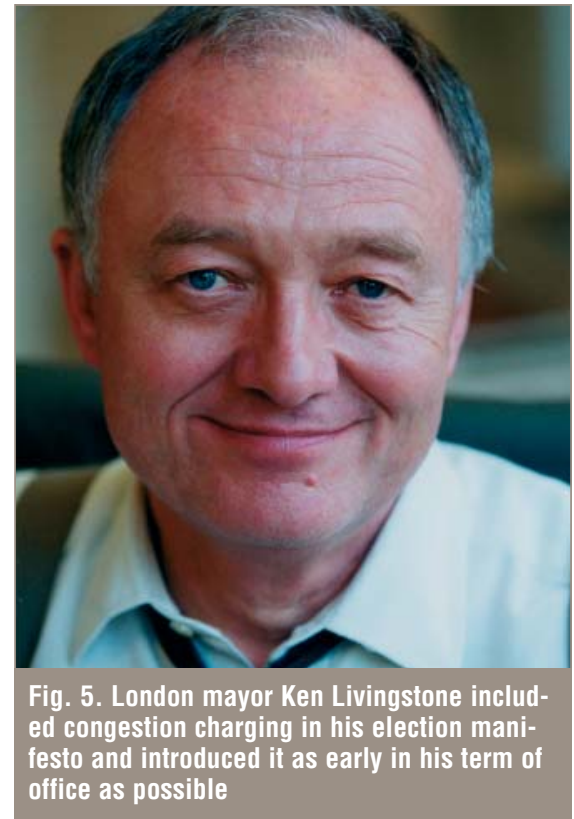

was seen as essential in terms of successful implementation of congestion charging in central London. Prior to the launch of the scheme, a public information exercise was undertaken involving radio, television and newspaper campaigns and the development of a detailed website. Leaflets were also delivered to every household in London outlining the extent of the charging zone and who would be affected.

\section{Political will and leadership}

When selling the concept of congestion charging, political stability would appear to be a prerequisite. Certainly in terms of congestion charging in central London the role of the mayor, Ken Livingstone, should not be underestimated (Fig. 5). $\mathrm{He}$ included the notion of a congestion-charging scheme in his electoral manifesto and as such people voted for him in full knowledge that, if at all possible, he would introduce a congestion-charging scheme if elected. He was duly elected and the congestion-charging scheme was introduced early enough in the mayor's term of office to avoid political instability.

When selling such a scheme, positive political will and leadership are paramount. This is important given the current debate about developing a national charging scheme in the UK and a lorry road-user charge.

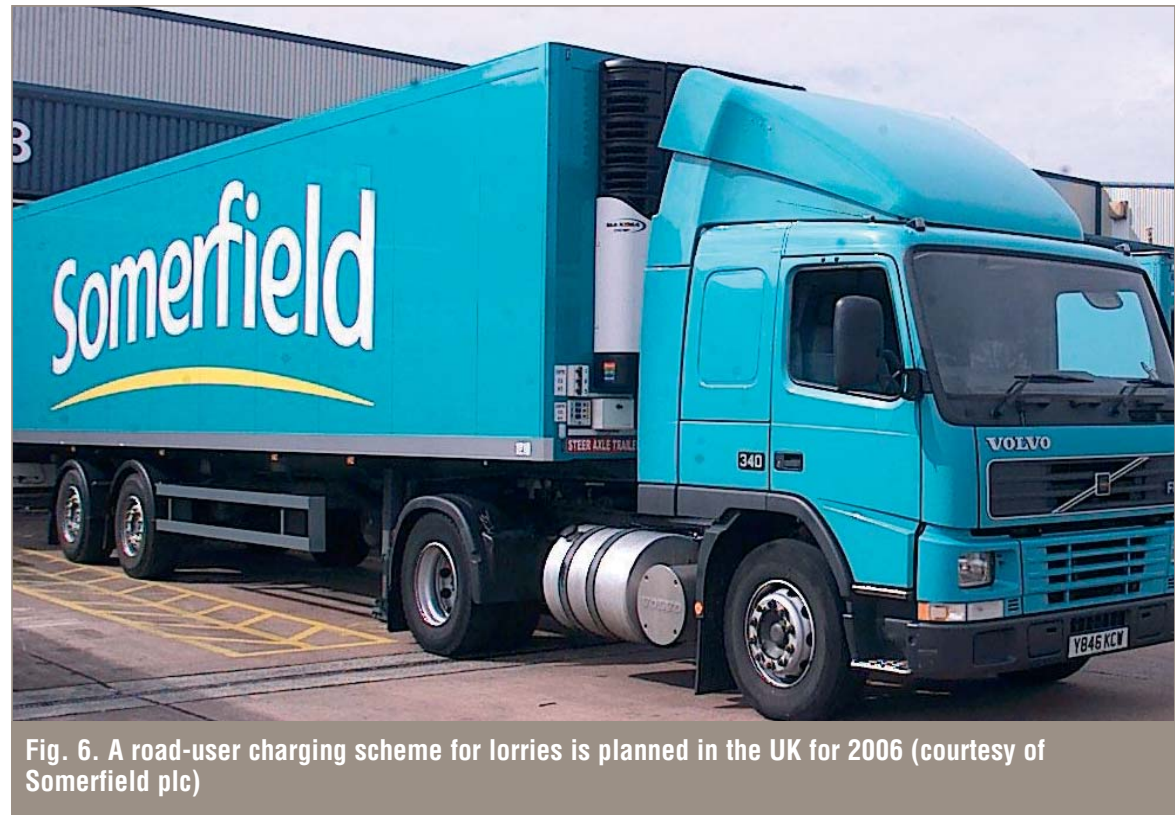

In terms of a national charging scheme, in 2003 the UK Government set up a comprehensive study examining issues surrounding a new system of charging for road use nationally. ${ }^{18}$ According to the study

'The key to a fully national road pricing scheme is a technology which can charge by time, distance and place to target costs, including environmental costs. Most costs are caused by congestion. Targeting congestion might require a complex 'box' on board the vehicle which could work out exactly where, when and over what distance the vehicle was being used, possibly using a positioning system, although the technology requirement will depend on the precise requirements of the scheme, and on technological developments over time.'

The study, however, estimates that the necessary equipment will not be available in a mass-market and low-cost form until 2014 at the earliest. The cost of introducing a national road-pricing scheme should not be underestimated. There are the setup costs, the cost of enforcement and the administrative system necessary to deal with payments and enquiries. The study estimated that the system 'could cost as much as $£ 3$ billion a year to run’.

One of the main benefits of a national road-user charging scheme is its ability to address congestion when and where it occurs, something current motoring taxes cannot achieve. Implementation would represent a major challenge, not least in terms of installing on-board technology in vehicles, liaison between national and local government to establish when and where charging should apply, and whether a national charge should totally or partially replace fuel duty.

In April 2002 it was announced that a UK-wide road-user charging scheme for all lorries would be introduced from around 2006 with a corresponding reduction in the duty on fuel (Fig. 6). The exact time of implementation will be based on the desire to ensure that quality and reliability of the scheme is established. One of the important aspects of the desire to implement such a scheme is to ensure that foreign haulage operators pay their fair share towards the cost of using the road network in the UK. In this respect the charging objective is clear, namely one of fairness and efficiency with road users contributing in relation to the costs they impose in the UK in terms of climate change, local air quality, road maintenance, traffic congestion, noise and safety. This is based in part on the theoretical underpinning of roaduser charging outlined above. 
Edinburgh Council recently considered implementing a $£ 2$ per day, twin-cordon congestion charge but the scheme was defeated in a referendum in February 2005. The intention was to utilise the surplus charging revenue to fund transport improvements, most notably park-andride sites, enhanced bus services and the Edinburgh tram.

For developing a national road-user charging scheme and haulage scheme, positive political will and leadership are clearly vital.

\section{Conclusion}

Congestion charging is increasingly being seen as a policy option capable of dealing with the problem of congestion in urban areas. The main difficulty, however, is one of acceptance and therefore the concept needs to be sold.

The authority implementing the charge is likely to be seen as the main beneficiary, namely through the revenue raised, and careful consideration needs to be given to explain how that revenue is to be used. This is important not only for those who continue to use the road but also those who are 'priced off the road'.

Clearly improved public transport facilities are required. For a policy such as congestion charging to be accepted there is a clear need for a congestion problem to be seen to exist. In central London such a problem was seen to exist, and it was against this backdrop that congestion charging was successfully introduced.

Technological advances have meant that a sophisticated congestion-charging scheme could be introduced, one closely related to the level of congestion experienced. In 'selling' the concept, however, it may be necessary to introduce a simple scheme in the first instance. This may be part of a package of measures that can be provided if the revenue raised from congestion charging is hypothecated. Any new concept, and certainly one as contentious as congestion charging, requires promoting.

Political stability would also seem to be all-important. A change in political complexion and/or political leadership can severely affect the chances of a congestion charge being introduced.
References

I. JONES P. M. (1998) Urban road pricing: public acceptability and barriers to implementation. In Road Pricing, Traffic Congestion and the Environment (BUTTON K. J. and VERHOEF E.T. (eds). Edward Elgar, Cheltenham, 1998, 263-284.

2. ISON S. and WALL S. Market- and non-market-based approaches to traffic-related pollution: the perception of key stakeholders. International Journal of Transport Management, 2003, I, No. 3, |33-|43.

3. IsON S. Local Authority and Academic Attitudes to Urban Road Pricing: A UK Perspective, Transport Policy, 2000, 7, No. 4, 269-277.

4. IsON S. Road User Charging: Issues and Policies. Ashgate Publishing, Aldershot, 2004.

5. Bell M. G. H., Quddus M.A. SCHMÖCKER J.-D. and Fonzone A. The Impact of the Congestion Charge on the Retail Sector. Centre for Transport Studies, Imperial College London, April 2004

6. TRANSPORT FOR LONDON. Congestion Charging: Update on Scheme Impacts and Operations. TFL, London, February 2004.

7. PIgou A. The Economics of Welfare. Macmillan, London, 1920.

8. WALTERS A. A. The theory and measurement of private and social cost of highway congestion. Econometrica, 1961, 29, No. 4, 676-699.

9. Department of THe EnVIRONMENT, Transport AND the Regions. A New Deal for Transport: Better for Everyone. Cm 3950, The Stationery Office, London, 1998.

10. COPLEY G. and DODGSON J. (2004) Evaluation of a national congestion charging system. Proceedings of the Institution of Civil Engineers, Transport, 157, No. 2, I 17-123.

II. Department Of THe EnVIRONMEnt, TRANSPORT AND THE Regions. Breaking the Logjam. The Stationery Office, London, 1998.

12. House OF COMmons TRANsport COMmitTeE. Urban Charging Scheme. Report and proceedings of the committee, HC390-I,Vol I. The Stationery Office, London, 2003.

13. HAU T. D. Electronic road pricing: developments in Hong Kong 1983-1989. Journal of Transport Economics and Policy, 1990, 24, No. 2, 203-214.

14. TRANSPORT FOR LONDON. Average traffic speeds in Greater London (miles per hour). Available at: http://www.tfl.gov.uk/tfl//tr2003/road-related-trends-2.shtml.

15. Road Charging Options for London (Rocol): A Technical Assessment. The Stationery Office, London, 2000.

16. Ison S. Pricing road space: back to the future? The Cambridge experience. Transport Reviews, 1996, 16, No. 2, 109-126.

17. BLYTHE P.T. Congestion charging: challenges to meet the UK policy objectives. Review of Network Economics, 2004, 3, 356-370.

18. DEPARTMENT FOR TRANSPORT. Feasibility study of road pricing in the UK-full report, London: July. Available at: www.dft.gov.uk.

\section{What do you think?}

